\title{
Investigation of class 1 integrons in Klebsiella pneumoniae clinical and microbiota isolates belonging to different phylogenetic groups in Recife, State of Pernambuco
}

\author{
Alexsandra Maria Silva Lima ${ }^{[1],[2],[3], ~ M a i ́ r a ~ E s p i ́ n d o l a ~ S i l v a ~ d e ~ M e l o ~}{ }^{[1]}$, Luiz Carlos Alves ${ }^{[2],[3],}$ \\ Fábio André Brayner ${ }^{[2],[3]}$ and Ana Catarina Souza Lopes ${ }^{[1]}$
}

[1]. Departamento de Medicina Tropical, Universidade Federal de Pernambuco, Recife, PE. [2]. Laboratório de Imunopatologia Keizo Asami, Universidade Federal de Pernambuco, Recife, PE. [3]. Centro de Pesquisas Aggeu Magalhães, Universidade Federal de Pernambuco, Recife, PE.

\begin{abstract}
Introduction: The high prevalence of Klebsiella pneumoniae infections is related to the ability of K. pneumoniae to acquire and disseminate exogenous genes associated with mobile elements, such as R plasmids, transposons and integrons. This study investigated the presence of class 1 integrons in clinical and microbiota isolates of $K$. pneumoniae belonging to different phylogenetic groups and correlated these results with the antimicrobial resistance profiles of the studied isolates. Methods: Of the 51 isolates of $K$. pneumoniae selected for this study, 29 were from multidrug-resistant clinical isolates, and 22 were from children's microbiota. The susceptibility profile was determined using the disk diffusion method, and class 1 integrons were detected through polymerase chain reaction (PCR). Results: The results showed that none of the 22 microbiota isolates carried class 1 integrons. Among the 29 clinical isolates, 19 (65.5\%) contained class 1 integrons, and resistance to sulfamethoxazole/ trimethoprim was identified in 18 of these isolates (94.7\%). Among the K. pneumoniae isolates with class 1 integrons, 47\% belonged to the KpI phylogenetic group, and one isolate (14.3\%) carrying these genetic elements belonged to the KpIII group. Conclusions: The wide variety of detected class 1 integrons supports the presence of high rates of antimicrobial resistance, genetic variability, and rapid dissemination of beta-lactamase genes among $K$. pneumoniae clinical isolates in recent years in hospitals in Recife-PE, Brazil. The findings of this study indicate that the surveillance of K. pneumoniae integrons in clinical isolates could be useful for monitoring the spread of antibiotic resistance genes in the hospital environment.
\end{abstract}

Keywords: Class 1 integron. Klebsiella pneumonia. Phylogenetic groups.

\section{INTRODUCTION}

Klebsiella pneumoniae is a bacillus that is commonly associated with serious nosocomial infections, such as septicemia, pneumonia, urinary tract infections, and meningitis ${ }^{1-3}$. This species is classified into three phylogenetic groups, KpI, KpII, and $\mathrm{KpIII}$, based on nucleotide variations in the constitutively expressed genes gyrA, parC, and $r p o B^{4,5}$. Mobile genetic elements, such as integrons, contribute to the evolution and dissemination of multidrug resistance genes $\left(b l a_{\mathrm{CTX}-\mathrm{M},}, b l a_{\mathrm{IMP}}\right.$ and $\left.b l a_{\mathrm{GES}}\right)$ in $K$. pneumoniae through horizontal or vertical transfer ${ }^{6-9}$. The mobile class 1 integrons are predominantly found in clinical isolates and are associated with transposon Tn21. Class 1 integrons are composed of two conserved regions, a $3^{\prime}$ conserved segment ( $3^{\prime} \mathrm{CS}$ ) and a $5^{\prime}$ conserved segment $\left(5^{\prime} \mathrm{CS}\right)$, as well as an internal variable region containing gene

Address to: Dr ${ }^{\mathrm{a}}$ Alexsandra Maria da Silva Lima. Dept $\underline{\underline{o}}$ Medicina Tropical/ UFPE. Av. Prof. Morais Rego s/n, 50732-970 Recife, PE, Brasil.

Phone: 5581 2126-8526; Fax: 5581 2126-8528

e-mail: alexsandramariah@gmail.com

Received 31 January 2014

Accepted 11 April 2014 cassettes that encode antimicrobial resistance determinants. The 3' CS segment contains the qacE $\Delta l$ and sul 1 genes, which confer resistance to ethidium bromide and quaternary ammonium compounds and to sulfonamide, respectively ${ }^{10-12}$. These genetic elements can be found in different species of Gram-negative bacteria ${ }^{13-17}$ from hospital environments. Based on the amino acid sequence of the IntI protein, five classes of mobile integrons have been described ${ }^{18}$. Classes 1,2 , and 3 are the most commonly detected $^{19}$. Class 1 integrons are the most widespread and have been frequently found in extended-spectrum $\beta$-lactamase (ESBL)producing clinical isolates of Enterobacteriaceae, including $K$. pneumoniae $e^{6,13,16,20,21}$. Class 2 integrons occur less frequently in ESBL-producing Escherichia coli and K. pneumoniae, and class 3 integrons are rarely found in ESBL-producing K. pneumoniae ${ }^{21,22}$.

Class 1 and class 2 integrons have also been found in Escherichia coli from fecal samples from healthy individuals in Spain, indicating that individuals from the community may serve as reservoirs for these genetic elements ${ }^{23}$. Nevertheless, no published study has correlated the presence of these genetic elements with $K$. pneumoniae phylogenetic groups or with microbiota isolates. Thus, the present study evaluated the presence of class 1 integrons in clinical and microbiota isolates of $K$. pneumoniae from different phylogenetic groups in Recife, Brazil, and it correlated their presence with the antimicrobial resistance profiles displayed by the isolates. 


\section{METHODS}

\section{Bacterial isolates}

A total of $51 \mathrm{~K}$. pneumoniae isolates already typed for phylogenetic group ${ }^{24}$ were analyzed for the presence of class 1 integrons. Twenty-nine of these isolates were from hospitalized patients from the City of Recife, Pernambuco, Brazil, and 22 were from normal oropharyngeal and fecal microbiota from healthy 3- to 4-year-old children attending a day care center called Lar Fabiano de Cristo in the Várzea district of Recife, Brazil (Table 1). All the cultures were stored in $20 \%$ glycerol at $-70^{\circ} \mathrm{C}$ and were grown at $37^{\circ} \mathrm{C}$ for $18 \mathrm{~h}$ in brain-heart infusion broth (BHI) or Luria-Bertani broth (LB).

\section{Antibiotic susceptibility analysis}

Antibiotic susceptibility was tested on Mueller-Hinton agar using the disk diffusion method Clinical and Laboratory Standards Institute (CLSI) ${ }^{25}$. The following antibiotics were tested: amoxicillin-clavulanate (AMC), amoxicillin (AMO), amikacin (AMI), ampicillin (AMP), aztreonam (ATM), ceftazidime (CAZ), cefotaxime (CTX), cefepime (CPM ), ciprofloxacin (CIP), chloramphenicol (CLO), streptomycin (EST), gentamicin (GEN), imipenem (IPM), kanamycin (KAN), nalidixic acid (NAL), sulfamethoprim (TSP), and tetracycline (TET).

\section{Genomic DNA extraction}

Genomic deoxyribonucleic acid (DNA) was extracted from direct colony suspensions in $200 \mu 1$ of distilled water. The suspensions were heated at $100^{\circ} \mathrm{C}$ for $10 \mathrm{~min}$ and centrifuged $(5 \mathrm{~min} / 10,000 \mathrm{xg})$, and $100 \mu \mathrm{l}$ of the recovered supernatant was stored at $-20^{\circ} \mathrm{C}$ until use.

\section{Detection of class 1 integrons through PCR}

Amplification reactions were prepared in a total volume of $25 \mu \mathrm{l}$ containing $1 \mathrm{ng}$ of genomic DNA, 2 units of Taq DNA polymerase (Promega), 200 $\mu \mathrm{M}$ of each deoxyribonucleotide triphosphate (dNTP) (Promega), $1.5 \mathrm{mM} \mathrm{MgCl}_{2}, 1 \mu \mathrm{M}$ of each primer (3'CS (AAGCAGACTTGACCTGAT) and $5^{\prime} \mathrm{CS}$ (GGCATCCAAGCAGCAAG), and $1 \mathrm{X}$ reaction buffer ${ }^{26}$. The cycling conditions were one cycle of $5 \mathrm{~min}$ at $95^{\circ} \mathrm{C} ; 30$ cycles of $1 \mathrm{~min}$ at $95^{\circ} \mathrm{C}, 1 \mathrm{~min}$ at $65^{\circ} \mathrm{C}$, and $1 \mathrm{~min}$ at $72^{\circ} \mathrm{C}$; and one cycle of $10 \mathrm{~min}$ at $72^{\circ} \mathrm{C}$. The amplification products were visualized in $1 \%$ agarose gels in Tris-borate buffer (TBE) buffer.

\section{RESULTS}

\section{Class 1 integrons}

Among the $51 \mathrm{~K}$. pneumoniae clinical and microbiota isolates analyzed in this work, $19(37.2 \%)$ carried class 1 integrons. Nineteen $(65.5 \%)$ of the 29 clinical isolates carried class 1 integrons, as indicated by amplicons ranging from 750 to $>2,080 \mathrm{bp}$. None of the 22 microbiota isolates carried these genetic elements (Table 1). Three clinical isolates (K5A, K10P, and K14P) contained two integrons each, with amplicon sizes ranging from 750 to $>2,080 \mathrm{bp}$. The examination of the relationship between the phylogenetic groups and the presence of class 1 integrons revealed that $16(80 \%)$ of the clinical isolates carrying class 1 integrons belonged to the KpI phylogenetic group. Clinical isolates from 1998 and 1999 exhibited lower integron frequencies compared with those from 2007 and 2008 (Table 1).

\section{Antimicrobial resistance}

The identified $K$. pneumoniae isolates with class 1 integrons exhibited the following high levels of resistance to antibiotics: AMP $100 \%(\mathrm{n}=19)$; AMO 57.9\% $(\mathrm{n}=11)$; AMC $42.1 \%(\mathrm{n}=8)$; CTX 94.7\% ( $\mathrm{n}=18)$; CAZ 73.7\% ( $\mathrm{n}=14)$; CPM 47.4\% ( $\mathrm{n}=9)$; and IPM and meropenem $36.8 \%(\mathrm{n}=7)$. In addition, resistance to sulfamethoxazole associated with trimethoprim was observed in $94.7 \%(\mathrm{n}=18)$ of these isolates, and resistance to monobactam aztreonam (ATM) was observed in $73.7 \%(n=14)$ of these isolates. The K. pneumoniae isolates were more susceptible to aminoglycosides, fluoroquinolones, and CLO than to penicillin, cephalosporin, sulfa, or monobactams. Eighteen (94.7\%) of the $K$. pneumoniae isolates carrying class 1 integrons exhibited simultaneous sulfamethoxazole/trimethoprim resistance. K10-R was the only isolate with one class 1 integron and no resistance to sulfamethoxazole/trimethoprim. Conversely, the K12-A and $\mathrm{K} 20$-P isolates did not contain class 1 integrons but displayed resistance to sulfamethoxazole/trimethoprim (Table 1).

\section{DISCUSSION}

This study investigated the presence of class 1 integrons in clinical and microbiota isolates of $K$. pneumoniae from different phylogenetic groups and correlated these results with the antimicrobial resistance profiles of the studied isolates. Few studies have evaluated the presence of class 1 integrons in $K$. pneumoniae isolates from the Brazilian northeast ${ }^{27}$. Chagas et al. ${ }^{20}$ showed that all $K$. pneumoniae ESBL-producing isolates from Rio de Janeiro and São Paulo, Brazil carried class 1 integrons. Ahangarzadeh Rezaee et al. ${ }^{13}$ found that integrons were widely prevalent in clinical isolates of $K$. pneumoniae from northwestern Iran and were associated with multidrug resistance. In the present study, class 1 integrons were identified in clinical isolates only; these results are similar to those reported by Dalsgaard et al. ${ }^{11}$ and confirm that integrons are predominantly found in clinical isolates.

Because no integrons were identified in the studied $K$. pneumoniae microbiota isolates from healthy individuals, we suggest that they are not reservoirs for class 1 integrons. Thus, K. pneumoniae clinical isolates are the main reservoirs for these genetic elements and disseminate them to other bacterial species through horizontal or vertical transfer in the hospital environment. Most of the clinical isolates carried one integron; however, the K5A, K10P, and K14P isolates each contained two integrons. This result is consistent with reports by Penteado et al. $^{28}$ and Lopes et al. ${ }^{27}$, who observed additional integrons in isolates and suggested the presence of high diversity in these genetic elements in K. pneumoniae isolates from Recife. The $3^{\prime}$ segment of class 1 integrons contains the sul 1 gene, 
TABLE 1 - Specimens, origins, phylogenetic groups, presence of class 1 integrons, and antimicrobial resistance profiles of Klebsiella pneumoniae isolates from Recife, Brazil.

\begin{tabular}{|c|c|c|c|c|c|c|}
\hline Isolates $^{\mathrm{a}}$ & Specimen $^{\mathrm{b}}$ & $\begin{array}{l}\text { Phylogenetic } \\
\text { group }\end{array}$ & Origin $^{c}$ & $\begin{array}{c}\text { Year of } \\
\text { isolation }\end{array}$ & Integron $^{\mathrm{bp}}$ & Antimicrobial resistance ${ }^{d}$ \\
\hline $\mathrm{K} 1 \mathrm{~A}$ & Hosp. & Kp I & Catheter & 2007 & 1,800 & AMO, AMP, NAL, AMC, ATM, CAZ, CTX, CLO (I), SZT \\
\hline $\mathrm{K} 2 \mathrm{~A}$ & Hosp. & Kp I & Urine & 2007 & 1,600 to $>2,080$ & AMO, AMP, NAL, AMC, ATM, CAZ, CTX, TET, SZT \\
\hline $\mathrm{K} 3 \mathrm{~A}$ & Hosp. & Kp III & Wound & 2007 & $>2,080$ & AMO, AMP, NAL (I), AMC, CTX (I), TET, SZT \\
\hline K4A & Hosp. & Kp III & Trach. aspirate & 2007 & Negative & AMO, AMP, NAL, CTX (I), TET \\
\hline K5A & Hosp. & Kp I & Urine & 2007 & 1,300 to 2,080 & AMO, AMP, AMC, ATM, CAZ, CTX, TET, CLO, SZT \\
\hline K7A & Hosp. & $\mathrm{Kp} I$ & Trach. aspirate & 2007 & 1,800 & AMO, AMP, NAL, AMC, ATM, CAZ, CTX, TET, SZT \\
\hline K8A & Hosp. & Kp I & Blood & 2007 & 1,500 & AMO, AMP, NAL (I), TET, SZT \\
\hline K9A & Hosp. & Kp I & Trach. Aspirate & 2007 & 2,000 & AMO, AMP, AMC, ATM, CAZ, CTX, CLO, SZT \\
\hline K10A & Hosp. & Kp I & Urine & 2007 & 2,080 & AMO, AMP, NAL, AMC, ATM, CAZ, CTX, TET, CLO, SZT \\
\hline K12A & Hosp. & Kp I & Urine & 2007 & Negative & AMO, AMP, SZT \\
\hline K1P & Hosp. & Kp I & Urine & 2008 & 1,800 & AMP, ATM, CPM, CTX, CAZ, IPM, SZT \\
\hline $\mathrm{K} 4 \mathrm{P}$ & Hosp. & Kp II & Sputum & 2008 & Negative & AMP \\
\hline K5P & Hosp. & $\mathrm{Kp} I$ & Blood & 2008 & 1,800 & AMP, ATM, CPM, CTX, CAZ, IPM, SZT \\
\hline K8P & Hosp. & $\mathrm{Kp} I$ & Urine & 2008 & 1,800 & AMI, AMP, ATM, CPM, CTX, CAZ, GEN, IPM, SZT \\
\hline K10P & Hosp. & Kp I & Trach. aspirate & 2008 & 1,600 to 750 & AMP, ATM, CPM, CTX, CAZ, CIP, IPM, SZT \\
\hline $\mathrm{K} 12 \mathrm{P}$ & Hosp. & Kp I & Urine & 2008 & 1,800 & AMP, ATM, CPM, CTX, CAZ, CIP, GEN, IPM, SZT \\
\hline K13P & Hosp. & Kp I & Trach. aspirate & 2008 & 1,600 & AMP, ATM, CPM, CTX, CAZ, CIP, GEN, IPM, SZT \\
\hline $\mathrm{K} 14 \mathrm{P}$ & Hosp. & Kp I & Blood & 2008 & 1,800 to $>2,080$ & AMP, ATM, CPM, CTX, CAZ, CIP, GEN, SZT \\
\hline $\mathrm{K} 15 \mathrm{P}$ & Hosp. & Kp I & Urine & 2008 & 1,500 & AMP, ATM, CPM, CTX, CAZ, CIP, IPM, SZT \\
\hline K20P & Hosp. & $\mathrm{Kp} I$ & Urine & 2008 & Negative & AMP, ATM, CPM, CTX, CAZ, CIP, GEN, IPM, SZT \\
\hline K10-R & Hosp. & Kp II & Trach. aspirate & 1998 & 1,300 & AMP, AMO, CLO (I), TET (I), EST (I), CTX (I) \\
\hline $\mathrm{K} 15-\mathrm{R}$ & Hosp. & Kp I & Blood & 1998 & Negative & AMI (I), AMP, AMO, AMC, CLO, CTX, GEN, KAN(I), TET(I) \\
\hline K16-R & Hosp. & Kp I & Urine & 1998 & $>2,000$ & AMP, AMO, AMC(I), CLO, CPM, GEN, KAN, EST, ATM, CTX, SZT \\
\hline $\mathrm{K} 18-\mathrm{R}$ & Hosp. & Kp II & Urine & 1998 & Negative & AMP, AMO, TET (I) \\
\hline K20-R & Hosp. & Kp II & Urine & 1998 & Negative & AMP, AMO, TET (I), CTX (I) \\
\hline $\mathrm{K} 7-\mathrm{C}$ & Hosp. & Kp II & Urine & 1999 & Negative & AMP, AMO, CTX(I) \\
\hline $\mathrm{K} 10-\mathrm{C}$ & Hosp. & Kp I & Urine & 1999 & Negative & AMP, AMO, AMC (I), CLO, TET (I), NAL, ATM, CAZ (I), CTX (I) \\
\hline $\mathrm{K} 12-\mathrm{C}$ & Hosp. & Kp II & Urine & 1999 & 750 & AMP, AMO, CLO, TET, CTX (I), SZT \\
\hline K17-C & Hosp. & Kp III & Urine & 1999 & Negative & AMP, AMO, CLO (I) \\
\hline K3.1-F & Microb. & Kp III & Fecal & 2004 & Negative & KAN (I) \\
\hline K3.2-F & Microb. & Kp II & Fecal & 2004 & Negative & AMP, AMO, KAN (I) \\
\hline K6.3-F & Microb. & Kp I & Fecal & 2004 & Negative & AMP, AMO, EST (I) \\
\hline K7.1-F & Microb. & Kp I & Fecal & 2004 & Negative & AMP, AMO \\
\hline $\mathrm{K} 7.2-\mathrm{F}$ & Microb. & $\mathrm{Kp} \mathrm{I}$ & Fecal & 2004 & Negative & AMP, AMO, KAN (I), EST (I) \\
\hline $\mathrm{K} 10.1-\mathrm{F}$ & Microb. & Kp II & Fecal & 2004 & Negative & AMP, AMO \\
\hline $\mathrm{K} 10.2-\mathrm{F}$ & Microb. & Kp I & Fecal & 2004 & Negative & AMP, AMO, TET \\
\hline K13.3-F & Microb. & Kp II & Fecal & 2004 & Negative & AMP, AMO, KAN (I), EST (I) \\
\hline$\underline{\mathrm{K} 21.1-\mathrm{F}}$ & Microb. & Kp III & Fecal & 2004 & Negative & AMO (I), EST (I), KAN (I) \\
\hline
\end{tabular}


TABLE 1 - Continuation.

\begin{tabular}{|c|c|c|c|c|c|c|}
\hline Isolates $^{\mathrm{a}}$ & Specimen $^{\mathrm{b}}$ & $\begin{array}{l}\text { Phylogenetic } \\
\text { group }\end{array}$ & Origin $^{c}$ & $\begin{array}{l}\text { Year of } \\
\text { isolation }\end{array}$ & Integron $^{\mathrm{bp}}$ & Antimicrobial resistance ${ }^{\mathrm{d}}$ \\
\hline $\mathrm{K} 21.2-\mathrm{F}$ & Microb. & $\mathrm{Kp} \mathrm{I}$ & Fecal & 2004 & Negative & AMP, AMO \\
\hline $\mathrm{K} 24.2-\mathrm{F}$ & Microb. & $\mathrm{Kp} \mathrm{I}$ & Fecal & 2004 & Negative & AMP, AMO \\
\hline K51.1-F & Microb. & Kp I & Fecal & 2004 & Negative & AMP, AMO \\
\hline K58.2-F & Microb. & Kp I & Fecal & 2004 & Negative & AMP, AMO, KAN (I) \\
\hline K63.1-F & Microb. & Kp I & Fecal & 2004 & Negative & AMP, AMO, KAN (I) \\
\hline K63.2-F & Microb. & $\mathrm{Kp} \mathrm{I}$ & Fecal & 2004 & Negative & AMP, AMO, KAN (I), EST (I) \\
\hline $\mathrm{K} 68-\mathrm{F}$ & Microb. & $\mathrm{Kp} I$ & Fecal & 2004 & Negative & AMP, AMO, KAN (I) \\
\hline K2.3-ORO & Microb. & Kp III & Oropharyngeal & 2003 & Negative & AMO \\
\hline K112.1-ORO & Microb. & Kp I & Oropharyngeal & 2003 & Negative & AMO, AMP \\
\hline
\end{tabular}

Kp: Klebsiella pneumonia; bp: base pairs; IPM: imipenem; KAN: kanamycin; AMO: amoxicillin; AMP: ampicillin; NAL: nalidixic acid; AMC: amoxicillin-clavulanate; ATM: aztreonam; CAZ: ceftazidime; CTX: cefotaxime; CLO: chloramphenicol; SZT: trimethoprim/ sulfamethoxazole; TET: tetracycline; EST: streptomycin; I: intermediate susceptibility. KAN: kanamycin. ${ }^{a}$ Isolates: K: K. pneumoniae;

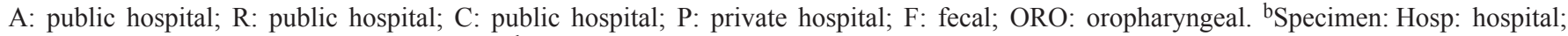
Microb: microbiota. ${ }^{\mathrm{c}}$ Origin: Trach: tracheal. ${ }^{\mathrm{d}}$ Resistance profile.

which encodes sulfonamide resistance. The K10-R isolate carried a class 1 integron but did not exhibit sulfamethoxazole/ trimethoprim resistance. The most likely reason for this result is that this isolate does not express the sull gene. Our study confirmed a correlation between sulfamethoxazole/trimethoprim resistance and the presence of class 1 integrons: $94.7 \%$ of the analyzed isolates carried class 1 integrons and exhibited sulfamethoxazole/trimethoprim resistance ${ }^{29,30}$. The K12-A and $\mathrm{K} 20-\mathrm{P}$ isolates did not carry class 1 integrons but displayed sulfamethoxazole/trimethoprim resistance. The sull gene encodes resistance to sulfonamides only, and we evaluated the associated sulfamethoxazole/trimethoprim. The most common mechanism of trimethoprim resistance involves variants of the dihydrofolate reductase (DFR), and the absence of class 1 integrons in these two isolates suggests that they may express the $d f r A$ gene and that this gene could be located in other genetic elements, such as plasmids, transposons and chromosomes, which could explain our findings ${ }^{31-34}$. We observed that isolates belonging to the $\mathrm{KpI}$ phylogenetic group had the highest frequency of class 1 integrons; some class 1 integrons were observed in isolates from the KpII group, but very few were observed in isolates from the KpIII group. This high frequency of class 1 integrons is one of the factors explaining why isolates from the KpI group presented the highest level of resistance, followed by isolates from the $\mathrm{KpII}$ group and isolates from the KpIII group ${ }^{4}$. We also observed that the frequency and diversity of class 1 integrons in the $K$. pneumoniae clinical isolates in Recife increased between 1998 and 1999 and between 2007 and 2008. This result is consistent with the observed rapid dissemination of beta-lactamase genes along with resistance to extended-spectrum cephalosporins and carbapenems among $K$. pneumoniae clinical isolates in Recife in recent years ${ }^{35}$. In this study, the diversity of class 1 integrons in $K$. pneumoniae isolates from Recife, Brazil favors the dissemination of resistance among $K$. pneumoniae and other species in the hospital environment. Moreover, this study also indicates that the surveillance of $K$. pneumoniae integrons in clinical isolates could be useful for monitoring the spread of antibiotic resistance genes in the hospital environment.

\section{FINANCIAL SUPPORT}

Fundação de Amparo à Ciência e Tecnologia do Estado de Pernambuco (FACEPE) for financial support.

\section{CONFLICT OF INTEREST}

The authors declare that there is no conflict of interest.

\section{REFERENCES}

1. Minarini LA, Gales AC, Palazzo IC, Darini Al. Prevalence of community-occurring extended spectrum beta-lactamase-producing Enterobacteriaceae in Brazil. Curr Microbiol 2007; 54:335-341. 
2. Pan YJ, Fang HC, Yang HC, Lin TL, Hsieh PF, Tsai FC, et al. Capsular Polysaccharide Synthesis Regions in Klebsiella pneumoniae Serotype K57 and a New Capsular Serotype. J Clin Microbiol 2008; 46:2231-2240.

3. Tu YC, Lu MC, Chiang MK, Huang SP, Peng HL, Chang HY, et al. Genetic requirements for Klebsiella pneumoniae induced liver abscess in oral infection model. Infec Immu 2009; 77:2657-2671.

4. Brisse S, Van Himbergen T, Kusters K, Verhoef J. Development of a rapid identification method for Klebsiella pneumoniae phylogenetic groups and analysis of 420 clinical isolates. Clin Microbiol Infec 2004; 10:942-945.

5. Fevre C, Passet V, Weil FX, Grimont PAD, Brisse S. Variants of the Klebsiella pneumoniae OKP chromosomal beta-lactamase are divided into two main groups, OKP-A and OKP-B. Antimicrob Agents Chemother 2005; 49:5149-5152.

6. Chen L, Chavda KD, Fraimow HS, Mediavilla JR, Melano RG, Jacobs MR, et al. Complete nucleotide sequences of blaKPC-4- and blaKPC-5harboring IncN and IncX plasmids from Klebsiella pneumoniae strains isolated in New Jersey. Antimicrob Agents Chemother 2013; 57:269-276.

7. Hussain A, Ewers C, Nandanwar N, Guenther S, Jadhav S, Wieler LH, et al. Multiresistant uropathogenic Escherichia coli from a region in India where urinary tract infections are endemic: Genotypic and phenotypic characteristics of sequence type 131 isolates of the CTXM-15 extendedspectrum- $\beta$-lactamase-producing lineage. Antimicrob Agents Chemother 2012; 56:6358-6365.

8. Martínez T, Vazquez GJ, Aquino EE, Goering RV, Robledo IE. Two novel class I integron arrays containing IMP-18 metallo- $\beta$-lactamase gene in Pseudomonas aeruginosa clinical isolates from Puerto Rico. Antimicrob Agents Chemother 2012; 56:2119-2121.

9. Bebrone C, Bogaerts P, Delbrück H, Bennink S, Kupper MB, Rezende de Castro R, et al. GES-18, a new carbapenem-hydrolyzing GES-type $\beta$-Lactamase from Pseudomonas aeruginosa that contains Ile80 and Ser170 Residues. Antimicrob Agents Chemother 2013; 57:396-401.

10. Levesque C, Piche L, Larose C, Roy PH. PCR mapping of ntegrons reveals several novel combinations of resistence genes. Antimicrob Agents Chemother 1995; 39:185-191.

11. Dalsgaard A, Forslund A, Petersen A, Brown DJ, Dias F, Monteiro S, et al. Class 1 Integron-Borne, Multiple-Antibiotic Resistance Encoded by a 150-Kilobase Conjugative Plasmid in Epidemic Vibrio cholerae O1 Strains Isolated in Guinea-Bissau. J Clin Microbiol 2000; 38:3774-3779.

12. Martínez N, Mendonza MC, Rodriguez I, Soto S, Bances M, Rodicio R. Detailed structure of integrons and transposons carried by large conjugative plasmids responsible for multidrug resistance in diverse genomic types of Salmonella enterica serovar Brandenburg. J Antimicrob Chemother 2007; 60:1227-1234.

13. Ahangarzadeh Rezaee M, Langarizadeh N, Aghazadeh M. First report of class 1 and class 2 integrons in multidrug-resistant Klebsiella pneumoniae isolates from northwest Iran. Jpn J Infect Dis 2012; 65:256-259.

14. Carneiro C, Araújo C, Gonçalves A, Vinué L, Somalo S, Ruiz E, et al. Detection of CTX-M-14 and TEM-52 extended-spectrum beta-lactamases in fecal Escherichia coli isolates of captive ostrich in Portugal. Foodborne Pathog Dis 2010; 7:991-994

15. Ingold AJ, Castro M, Nabón A, Borthagaray G, Márquez C. VIM-2 metallo- $\beta$-lactamase gen detection in a class 1 integron associated to bla(CTX-M-2) in a Pseudomonas aeruginosa clinical isolate in Uruguay: first communication. Rev Argent Microbiol 2011; 43:198-202.

16. Ibrahim N, Wajidi MF, Yusof MY, Tay ST. The integron prevalence of extended-spectrum beta-lactamase producing enterobacterial isolates in a Malaysian teaching hospital. Trop Biomed 2011; 28:668-671.

17. Taherikalani M, Maleki A, Sadeghifard N, Mohammadzadeh D, Soroush S, Asadollahi P, et al. Dissemination of class 1, 2 and 3 integrons among different multidrug resistant isolates of Acinetobacter baumannii in Tehran hospitals, Iran. Pol J Microbiol 2011; 60:169-174.

18. Cambray G, Guerout AM, Mazel D. Integrons. Annu Rev Genet 2010; 44:141-166.
19. Stalder T, Barraud O, Casellas M, Dagot C, Ploy MC. Integron Involvement in Environmental Spread of Antibiotic Resistance. Frontiers Microbiol 2012; 3:119.

20. Chagas TP, Alves RM, Vallim DC, Seki LM, Campos LC, Asensi MD. Diversity of genotypes in CTX-M-producing Klebsiella pneumoniae isolated in different hospitals in Brazil. Braz J Infect Dis 2011; $15: 420-425$.

21. Mobarak-Qamsari M, Ashayeri-Panah M, Eftekhar F, Feizabadi MM. Integron mediated multidrug resistance in extended spectrum betalactamase producing clinical isolates of Klebsiella pneumoniae. Braz J Microbiol 2014; 44:849-854.

22. Bhattacharjee A, Sen MR, Prakash P, Gaur A, Anupurba S, Nath G. Observation on integron carriage among clinical isolates of Klebsiella pneumoniae producing extended spectrum $\beta$-lactamases. Ind J Med Microbiol 2010; 28:207-210.

23. Vinué L, Sáenz Y, Somalo S, Escudero E, Moreno MA, Ruiz-Larrea F, et al. Prevalence and diversity of integrons and associated resistance genes in faecal Escherichia coli isolates of healthy humans in Spain. J Antimicrob Chemother 2008; 62:934-937.

24. Melo MES, Cabral AB, Maciel MAV, Silveira VM, Lopes ACS. Phylogenetic Groups among Klebsiella pneumoniae isolates from Brazil: Relationship with antimicrobial resistance and origin. Current Microbiology 2011; 62:1596-1601.

25. Clinical and Laboratory Standards Institute (CLSI). Performance standards for antimicrobial susceptibility testing. $23^{\text {th }}$ informational supplement. CLSI M100-S23. Wayne, PA: CLSI; 2013.

26. Bissonnette L, Roy PH. Characterization of In0 of Pseudomonas aeruginosa plasmid pVS1, an ancestor of integrons of multiresistance plasmids and transposons of gram-negative bacteria. J bacteriol 1992; 174:1248-1257.

27. Lopes ACS, Veras DL, Lima AMS, Melo RCA, Ayala J. bla ${ }_{\text {Стх-м-2; }}$ and bla ${ }_{\text {СTX-M-28 }}$ extended-spectrum $\beta$-lactamase genes and class 1 integrons in clinical isolates of Klebsiella pneumoniae from Brazil. Mem Inst Oswaldo Cruz 2010; 105:163-167.

28. Penteado AP, Castanheira M, Pignatari ACC, Guimarães T, Mamizuka EM, Gales AC. Dissemination of blaIMP-1- carrying integron In86 among Klebsiella pneumoniae isolates harboring a new trimethoprim resistance gene dfr23. Diagn Microbiol Infect Dis 2009; 63:87-91.

29. Agersø Y, Peirano G, Aarestrup FM. dfrA25, a novel trimethoprim resistance gene from Salmonella agona isolated from a human urine sample in Brazil. J Antimicrob Chemother 2006; 58:1044-1047.

30. Beutlich J, Rodriguez I, Schroeter A, Kasbohrer A, Helmuth R, Guerra B. A predominant multidrug-resistant Salmonella enteric seroval saintpaul clonal line in German Turkey and related food products. Appl Environ Microbiol 2010; 76:3657-3667.

31. Grape M, Sundström L, Kronvall G. Two new dfr genes in trimethoprimresistant integron-negative Escherichia coli isolates. Antimicrob Agents Chemother 2007; 51:1863-1864.

32. Wei Q, Xiaofei Jiang X, Yang Z, Chen N, Chen X, Li G, Lu Y. dfrA27, a new integron-associated trimethoprim resistance gene from Escherichia coli. J Antimicrob Chemother 2009; 63:405-419.

33. Perez-Roth E, Kwong SM, Alcoba-Florez J, Firth N, Alvarez SM. Complete Nucleotide Sequence and Comparative Analysis of pPR9, a 41.7-Kilobase Conjugative Staphylococcal Multiresistance Plasmid Conferring High-Level Mupirocin Resistance. Antimicrob Agents Chemother 2010; 54:2252-2257.

34. Toro M, Rojo-Bezares B, Vinue' L, Undabeitia E, Torres C, Yolanda S. In vivo selection of aac $\left(6^{\prime}\right)-\mathrm{Ib}-\mathrm{cr}$ and mutations in the gyrA gene in a clinical qnrS1-positive Salmonella enterica serovar Typhimurium DT104B strain recovered after fluoroquinolone treatment. J Antimicrob Chemother 2010; 65: 1945-1949.

35. Cabral AB, Melo RCA, Maciel MAV, Lopes ACS. Multidrug resistance genes, including blaKPC and blaCTX-M-2, among Klebsiella pneumoniae isolated in Recife, Brazil. Rev Soc Bras Med Trop 2012; 45:572-578. 